\title{
Peripheral outpatient clinics: Use, costs, and benefits
}

\author{
M. J. GOLDACRE AND A. GATHERER
}

From the Department of Social and Community Medicine, University of Oxford, and the Oxfordshire Area Health Authority

SUMMARY A census was taken of outpatient bookings at all hospitals and health centres in Oxfordshire for the main medical and surgical specialities. Nine per cent of all bookings were to peripheral clinics (that is, those outside the two main medical centres at Oxford and Banbury). About half of all bookings in the area were made to clinics within three or four miles of the patients' homes. The work load at peripheral clinics was mainly local: $75 \%$ of all patients at these clinics lived in the town or parishes adjacent to the town where the clinic was held. Peripheral clinics were associated with a lower work load at central clinics, but a higher overall work load from the town in which they were sited.

Centralisation of medical services has been favoured in recent years: 'The District General Hospital offers the most practicable way of placing the full range of hospital facilities at the disposal of patients and this consideration far outweighs the disadvantages of longer travel for some patients' (Department of Health and Social Security, 1962). In the report The Functions of the District General Hospital it was doubted that it would be economic to bring specialist staff from the district general hospital to conduct outpatient clinics in peripheral centres (Department of Health and Social Security, 1969). This view has been challenged (Gruer, 1971), and peripheral clinics have their advocates (Draper, 1967; Scott et al., 1975; Weller, 1975). This paper summarises the use made of peripheral clinics in the Oxfordshire area and discusses some of their costs and benefits.

\section{Population and method}

In Oxfordshire two main medical centres (Oxford and Banbury) offer a comprehensive range of services; and there are 11 specialities which hold 49 local clinical sessions in one or more of 10 peripheral towns. One-third of Oxfordshire's population lives in Oxford or Banbury or parishes adjacent to them; one-third lives in the 10 peripheral towns or adjacent parishes, and the remaining third lives scattered throughout the county.

A census of outpatients, booked to all outpatient sessions in the Oxfordshire area, was undertaken from 16 June to 12 July 1975 . If a clinic was cancelled, the next corresponding one was used in the survey. The method has been described in detail (Goldacre and Gatherer, 1977). In brief, information on each patient was obtained from the booking list and the patient's case-notes at the start and finish of each clinic. Patients' addresses were coded to parish level. Travelling distances were calculated in road-miles from a grid prepared by the Automobile Association. Distances saved by the use of peripheral clinics were calculated from the difference in miles between travel to the clinic of attendance and travel to the nearest alternative central clinic (that is, at Oxford or Banbury).

Results

Out of a total of 20085 outpatients $1853(9 \cdot 2 \%)$ were seen at peripheral clinics (Table 1). Conversely, of all patients from the 10 peripheral towns booked at all clinics in the area about a quarter were booked to a clinic in their home town (Table 2). A similar proportion of patients who lived in adjacent parishes to the town were booked to the local clinic. Most patients from Oxford and Banbury were, of course, booked at clinics in their home towns (the residual $2 \%$ in Table 2 represents patients from Banbury who travelled to clinics in

Table 1 Number and percentage of patients by site of clinic

\begin{tabular}{lllll}
\hline \multirow{3}{*}{ Patients } & \multicolumn{3}{l}{ Site of clinic } & \multirow{2}{*}{ Total } \\
\cline { 2 - 4 } & Oxford & Banbury & Peripheral & \\
\hline No. & 15680 & 2552 & 1853 & 20085 \\
$\%$ & $78 \cdot 1$ & $12 \cdot 7$ & $9 \cdot 2$ & 100.0 \\
\hline
\end{tabular}


Table 2 Number and percentage of patients booked to local clinics by place of residence (all specialities)

\begin{tabular}{lccc}
\hline \multirow{2}{*}{ Place of residence } & \multicolumn{2}{l}{ No. of patients } & $\begin{array}{l}\text { Percentage of } \\
\text { patients at } \\
\text { local clinics }\end{array}$ \\
\cline { 2 - 4 } & Local clinics & All clinics & \\
\hline 10 peripheral towns & 1072 & 4335 & $24 \cdot 7$ \\
$\quad$ Adjacent parishes & 312 & 1367 & $22 \cdot 8$ \\
Oxford and Banbury & 6298 & 6438 & $97 \cdot 8$ \\
$\quad$ Adjacent parishes & 1355 & 1384 & $97 \cdot 9$ \\
Rest of Oxfordshire & - & 4127 & - \\
Subtotal: all Oxfordshire & 9037 & 17651 & $51 \cdot 2$ \\
Outside Oxfordshire & - & 2346 & - \\
Total & 9037 & 19997 & $45 \cdot 2$ \\
\hline
\end{tabular}

Address unknown for 88 patients

Oxford). Thus, in all, about half of all outpatients were seen at clinics within three or four miles of their homes.

The work load at peripheral clinics was usually local: $58 \%$ of all patients who attended these clinics lived in the same town and another $17 \%$ lived in parishes adjacent to the town were the clinic was held. Patients from further away tended to travel to central clinics even if a peripheral clinic was geographically closer (Goldacre and Gatherer, 1977).

In 34 of the 49 combinations of clinical speciality and peripheral town in which sessions were held, the overall booking rates (to both local and central clinics combined) were higher than the county average for the relevant speciality. It seemed possible that, because of local differences in the age structure of the population or social circumstances, the needs for medical care were greater in these towns. Accordingly, for each of the 10 towns a comparison was made between the booking rates for those specialities which held local clinics, and those specialities which did not. For each town an 'expected' number of attendances was calculated for each speciality from the county average booking rate for the speciality and the population of the town. The 'observed' number, the number of patients who were actually booked from the town for the speciality, was compared with the 'expected' number to give the proportion of bookings by which each town was above or below the county average for each speciality. Summarising the findings, firstly, for the 49 town speciality combinations where local clinics were held, total bookings were $26 \%$ above the county average (Table 3). Considering the same 10 towns, secondly, for the town speciality combinations where there was no local clinic, total bookings were $4 \%$ above the county average. Thus, higher than average booking rates from each town were, in general, associated only with those specialities which held a local clinic in the town.
Table 3 Observed and expected numbers of bookings from each of 10 peripheral towns for each speciality

\begin{tabular}{|c|c|c|c|c|c|}
\hline \multirow{3}{*}{ Specialities } & \multicolumn{2}{|l|}{ Bookings } & \multicolumn{3}{|c|}{ Patients seen locally } \\
\hline & \multirow{2}{*}{$\begin{array}{l}\text { Expected } \\
\text { No. }\end{array}$} & \multirow{2}{*}{$\begin{array}{l}\text { Observed } \\
\text { No. }\end{array}$} & \multirow{2}{*}{$\begin{array}{l}\frac{O-E}{E} \\
\%\end{array}$} & \multicolumn{2}{|c|}{$\begin{array}{l}\text { Patients booked } \\
\text { locally }\end{array}$} \\
\hline & & & & No. & $\%$ \\
\hline $\begin{array}{l}\text { With local } \\
\text { clinics }\end{array}$ & 2076 & 2618 & 26 & 1072 & 41 \\
\hline $\begin{array}{l}\text { Without local } \\
\text { clinics }\end{array}$ & 1652 & 1717 & 4 & - & - \\
\hline
\end{tabular}

In 39 of the 49 combinations of town specialities where local clinics were held, the booking rate at central (Oxford and Banbury) clinics was lower than the county average booking rate for the speciality. Peripheral clinics took $41 \%$ of the work load for the speciality from towns in which they were sited (Table 3 ).

Assuming that all patients at peripheral clinics $\dot{\omega}$ would otherwise have attended the nearest central o clinic, a total of 35797 patient-miles of travelling 응 was saved (a return journey of $19 \cdot 3$ miles $\$$ booking). A total of 2300 doctor-miles of travellin $\vec{c}$ was incurred.

The distribution of patients by age and sex w禺 similar at peripheral and central clinics. In particulag, there was no tendency for peripheral clinics to take a higher proportion of young children or of the $\vec{\theta}$ elderly than central clinics (Table 4). Eight per cem $\checkmark$ of outpatients booked at peripheral clinics di not keep their appointments, compared with $12 \%$ at central clinics.

Table 4 Number and percentage of patients by age 응 group who were booked at central clinics or peripheral $\stackrel{\curvearrowright}{\circledR}$ clinics (specialities which hold peripheral clinics only)

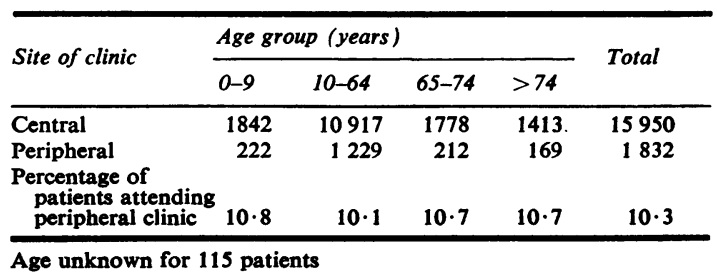

\section{Discussion}

The provision of local clinics in the 10 peripheral $\frac{D}{0}$ towns was usually associated with above average booking rates for the relevant speciality from the $N$ towns. The booking rates from these towns for $\mathrm{N}$ specialities which did not hold local clinics were, 옹 overall, only marginally above the county average. The possibility exists, and cannot be refuted, that clinics have been sited in each town for just $\stackrel{\circ}{=}$ those specialities where needs were greatest. 
However, comparing towns with substantially different population sizes (as these 10 towns have), priority for a local speciality clinic would more readily and more logically be perceived from the number of patients booked from each town than from the booking rate per 1000 population. We have shown that local clinics are not necessarily sited in towns where the number of bookings for each speciality is greatest (Goldacre and Gatherer, 1977). It seems unlikely that they would, nevertheless, have been sited in towns where the local booking rate was higher than average. It seems more likely that the $22 \%$ excess of bookings (Table 3 ) is largely a consequence of local clinic provision. Whether the higher rate associated with local clinics represents better care for the population or a degree of overbooking cannot be answered from this study.

Peripheral clinics took $41 \%$ of the total work load, representing a minimum net reduction of $19 \%$ in attendances at central clinics, for each speciality from towns in which they were sited. It was not certain that such a reduction in central clinic work load would be found. It had been suggested locally that providing peripheral clinics could actually increase the work load at central clinics by creating a substantial increase in patients at the local clinic who would then be referred in large numbers to the more comprehensive facilities of the central clinics. This does not seem to have happened.

Bookings at peripheral clinics were mainly local and few patients travelled to them from other nearby towns, even when such a journey was shorter than that to Oxford or Banbury. This may reflect the lack of awareness of where peripheral clinics are held, the provision of local transport, or the preferences of general practitioners and patients. It is important because it cannot be assumed that peripheral clinics will be used by patients from nearby towns without knowledge of referral patterns and local circumstances.

The criteria for establishing a local clinic are: knowledge of the number of patients who travel from a town to central clinics for a given speciality (which our census gave us), the distance of a town from the nearest available clinic, the availability of suitable clinic facilities, and the views of local consultants, general practitioners, and patients. The following costs and benefits of peripheral clinics need to be considered.

1. The capital and running costs, and the availability of ancillary staff, must be compared between clinics in city centres and peripheral towns.

2. In this area, peripheral clinics reduced attendances at central clinics but probably increased the total outpatient work load.

3. The provision of peripheral clinics incurs the cost of doctors' travelling but reduces the cost of patients' travelling. At the present level of clinic provision in Oxfordshire, assuming a travelling expense of $10 p$ per mile, the travelling of the doctors would have cost $£ 230$ in the four-week period. If all patients booked at peripheral clinics would otherwise have travelled to the nearest central clinic, and paid their own expenses, the additional cost to patients would have been $£ 3580$ for the period. The provision of local clinics may reduce the use made of the ambulance and hospital car service. Hospital transport is expensive (ambulance services in Oxfordshire cost $£ 1$ million in 1975) and a small reduction in its use could result in substantial savings.

4. When doctors travel between clinics during working time, holding peripheral clinics results in loss of the doctors' time. However, it reduces patients' time spent travelling and probably reduces the time taken off work to attend outpatient departments. Assuming an average travelling speed of 20 miles an hour, 115 hours of medical time were lost (equivalent to $333 \frac{1}{2}$ hour sessions) and 1790 hours of patients' time were saved in the four-week period. The saving of patients' productivity will be less than that implied by the saving of travelling time. Only a proportion of patients would be working at the time of their appointment; and only a proportion of these would be able to take less time off work to attend a peripheral rather than a central clinic. However, 20 miles an hour is probably an overestimate of travelling speed for patients who use public transport in rural areas. In principle, unless the doctors' productivity lost while travelling is greater than the sum of all his patients' lost productivity, the community gains when the doctor travels rather than his patients (Gruer, 1971).

5. Peripheral clinics have the disadvantage of fewer diagnostic and treatment facilities than clinics in central hospitals, although complex facilities may not be needed for a substantial proportion of outpatients (Hampton et al., 1975; Weller, 1975).

6. Peripheral clinics have an opportunity cost: the consultant is not available for emergencies 
or to take decisions on the management of patients at his central hospital. However, such clinics increase the opportunity for contact between the general practitioner and the consultant. They also make access to specialist medical care easier for patients. The last two benefits do not appear, in general, to result in reduced use of outpatient services, but the possibility that they may sometimes save inpatient admissions merits study.

We thank Mr John Graves and Mr Brian Heagney for assistance analysing the data, the Automobile Association for providing distance charts, and Professor M. P. Vessey for helpful advice.

Reprints from: M. J. Goldacre, Department of Social and Community Medicine, 8 Keble Road, Oxford.

\section{References}

Department of Health and Social Security (1962). $A$ Hospital Plan for England and Wales. HMSO: London.
Department of Health and Social Security (1969). The Functions of the District General Hospital. HMSO: London.

Draper, P. (1967). Community-care units and inpatient $\stackrel{8}{\stackrel{2}{2}}$ units as alternatives to the district general hospital. Lancet, 2, 1406-1409.

Goldacre, M. J., and Gatherer, A. (1977). Use of outpatient services: A simple approach to seeking information. The Hospital and Health Services Review, 73, 14-16.

Gruer, R. (1971). Economics of outpatient care. Lancet, \& 1, 390-394.

Hampton, J. R., Harrison, M. J. G., Mitchell, J. R. A., $\vec{\circ}$ Prichard, J. S., and Seymour, C. (1975). Relative $\overrightarrow{\vec{\omega}}$ contributions of history-taking, physical examination, $\stackrel{\sigma}{\sigma}$ and laboratory investigation to diagnosis and $\vec{D}$ management of medical outpatients. British Medical $\stackrel{\bigcirc}{\partial}$ Journal, 2, 486-489.

Scott, R., Sinclair, J., Chowdhury, S. D., Yates, A. J., ஸे and Milligan, J. (1975). Urology in a modern health N centre. British Medical Journal, 2, 321-323.

Weller, S. D. V. (1975). Peripheral paediatric clinics. Survey and medical audit. British Medical Journal, 390-393. 